\title{
Fault detection, classification and section identification on distribution network with D-STATCOM using ANN
}

\author{
Garima Netam and AnamikaYadav \\ Department of Electrical Engineering, National Institute of Technology, Raipur, CG, India
}

\section{(C2016 ACCENTS}

\begin{abstract}
This paper presents easy and efficient method of fault detection, fault classification and section identification in distribution networks with distribution static synchronous compensator (D-STATCOM) using artificial neural networks (ANN). The neural network uses Levenberg-Marquardt backpropagation algorithm for training. The D-STATCOM (average) model available in MATLAB has been modified to perform fault analysis. D-STATCOM is used for reactive power compensation, and regulates the system voltage by absorbing and generating reactive power. Fault is simulated for different function of D-STATCOM in which it absorbs reactive power like an inductor and generates reactive power like a capacitor. The present work reports the results of fault detection, fault classification and section identification whether it is forward fault and reverse fault in distribution network with D-STATCOM.
\end{abstract}

\section{Keywords}

Distributed network, D-STATCOM, ANN, Fault detection, Section identification, Fault classification, LevenbergMarquardt backpropagation algorithm.

\section{Introduction}

Nowadays, the flexible alternating current transmission system (FACTS) device is widely used in transmission and distribution system to enhance power transfer capability and stability of the power. There are so many devices which are used in transmission line but D-STATCOM is a shunt device which is used only in distribution networks. DSTATCOM is similar to STATCOM, but only difference is STATCOM is used in transmission level. The performance of D-STATCOM system is to reduce power quality problems and improve distribution system performance under all types of system related disturbances and system unbalance faults, such as line-to-line (LL) and double line to ground (DLG) faults etc. [1]. It improves the power quality like voltage fluctuations, voltage sag, voltage swell etc. The D-STATCOM operates when there is a sudden change in source voltage (increase/decrease), it absorbs or generates reactive power. In DSTATCOM two voltage source converter (VSC) and capacitor is used to provide the dc voltage to the VSC. The two modelling approaches (detailed and average model) are explained by the researcher in a $+3 /-3$ Mvar D-STATCOM on a $25 \mathrm{kV}$ network by comparing their static and dynamic performance.

\footnotetext{
*Author for correspondence
}

The detailed and average model is compared when system is changes from inductive to capacitive operation. Chopping of dc voltage is observed on detailed whereas average value is observed in average model [2]. Several methods exist for detecting, classifying and section identification on transmission line [3-16]. ANN is widely used for fault detection, fault classification and section identification. The researcher worked on fault detection, fault classification and direction estimation for uncompensated transmission lines [3-12]. Directional relay based on negative or zero sequence components or compensated post fault voltages are almost common [3,4] but the relay is slowly operating for all types of faults, travelling waves is proposed for reducing the operating time of directional relay $[5,6]$. The protection over doubly fed transmission line $[3,7]$ greater portion of the line length can be protected comparing to earlier techniques. The input training data of the recording devices was sampled using digital signal processing [8] for fault classification. The protective relay scheme based on discrete wavelet transform and ANN provide primary and backup protection of $99 \%$ to the line within quarter cycle time [9]. The adaptive neuro-fuzzy inference system approach is used for directional estimation in sectional transmission lines [10]. Fuzzy inference system is used to improve the performance of directional relaying, fault 
classification in transmission line. The fuzzy logic based relay is less complex and better than other AI based methods such as ANN, support vector machine, SVM and decision tree because training patterns is not required [11].

The researcher worked on fault detection, fault classification and direction estimation for compensated transmission lines [13-16]. Superimposed sequence components-based integrated impedance (SSCII) technique is used for fault detection and fault classification in shunt (Staticvar compensator) compensated line. The magnitude of SSCII is small for internal fault and very large for external faults [13]. ANN and wavelet transform is used for the protection of transmission line with FACTS (Thyristor-Controlled Series Capacitor) device [13]. Fault detection and direction estimation based on ANN [15]. The fault detection and fault classification is based on Wavelet Entropy used in FACTS Compensated Transmission lines, the FACTS device are static synchronous series compensators (SSSC) and Unified Power Flow Controller (UPFC) which is placed in the midpoint of the transmission line [16].

This paper presents Artificial Neural Network algorithm is applied for the fault detection, fault classification and section identification for forward and reverse fault in distribution network with DSTATCOM. Various combinations of fault resistance, fault inception angle, fault distance and type of fault are considered. The data used in this technique is obtained from the simulate model of DSTATCOM on a $25 \mathrm{kV}$ network, which is done on MATLAB. The result based on this algorithm is simple, fast and accurate.

\section{Operation of D-STATCOM}

D-STATCOM is a shunt device which is used to regulate the system voltage by generating and absorbing reactive power. The network is connected to the D-STATCOM through the transformer and DSTATCOM consists of PWM inverter and PWM inverter consist of two IGBT bridges. At the DC side of inverter, a capacitor provides dc link voltage and that capacitor takes power from the network for charging. The controller of D-STATCOM provides control to dc link voltage and bus voltage. The main role of D-STATCOM is to synchronize the bus voltage by generating and absorbing reactive power just like a thyristor static compensator (TSC). The transfer of reactive power between the network and D-STATCOM is possible through the leakage reactance of the coupling transformer by using a secondary voltage in phase with the primary voltage (network side). Secondary side is D-STATCOM and primary side is network. There are two conditions for operation which are (also shown in Figure 1):

- If the bus voltage is higher than the secondary voltage then the D-STATCOM absorbs reactive power like an inductor.

- If the bus voltage is lower than secondary voltage then the D-STATCOM generates reactive power like a capacitor.

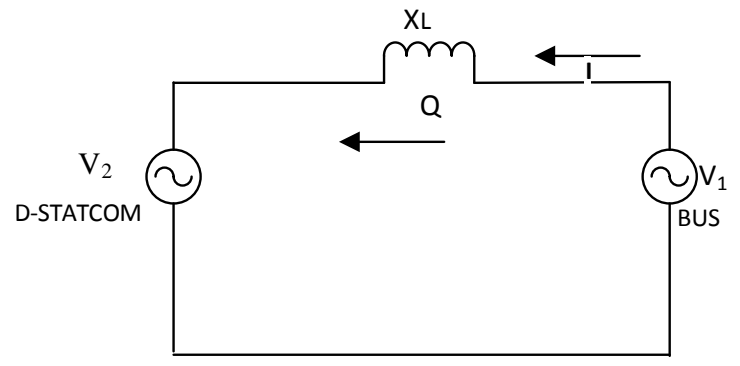

(a)

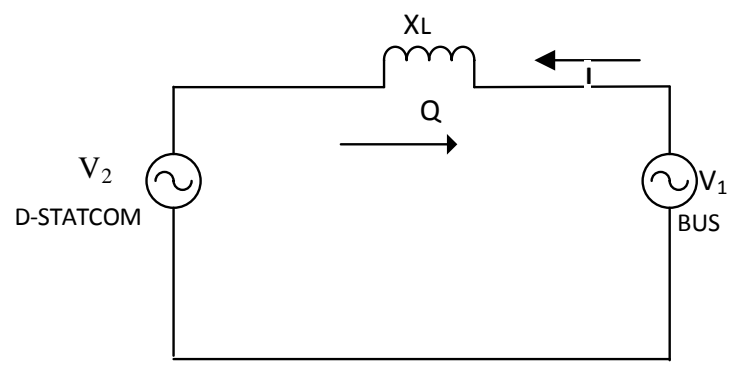

(b)

Figure 1 D-STATCOM operation (a) inductive operation (b) capacitive operation

In steady state condition D-STATCOM produces small active power to compensate the inverter losses and the bus voltage leads the inverter voltage by a small angle.

\section{Modelling of D-STATCOM}

The D-STATCOM is used to regulate the parameters of $25 \mathrm{kV}$ distributed network. We consider here, a +3/-3Mvar D-STATCOM connected to distribution network [2]. Two feeders of $21 \mathrm{~km}$ and $2 \mathrm{~km}$ are there which transmit power to the load. Feeder of 21 $\mathrm{km}$ is modelled by pi-equivalent circuit and connected between the bus 1 and bus 2, whereas 2 $\mathrm{km}$ feeder is connected between bus 2 and bus 3. For power factor correction, a shunt capacitor is added at bus 2 . Two different loads are connected to the bus 4 through distributed transformer of $25 \mathrm{kV} / 600 \mathrm{~V}$ and which are resistive load of $1 \mathrm{MW}$ and variable load. 
In D-STATCOM two voltage source converters are used which is consist of IGBT, 10,000 microfarad capacitor is used to provide dc to the voltage source converter and we get ac from the output side. An LC filter is used in output side of the inverter to provide quality factor and a resistance is connected in series with the capacitor. Voltage and current acquisition is done using anti-aliasing filter. Controller of DSTATCOM consists of Phase Locked Loop, and two measurements system (voltage and current) and DC voltage regulator. Simulink model of distribution network with D-STATCOM shown in Figure 2.

\section{5-KV, +3/-3 Mvar D istribution STATCOM}

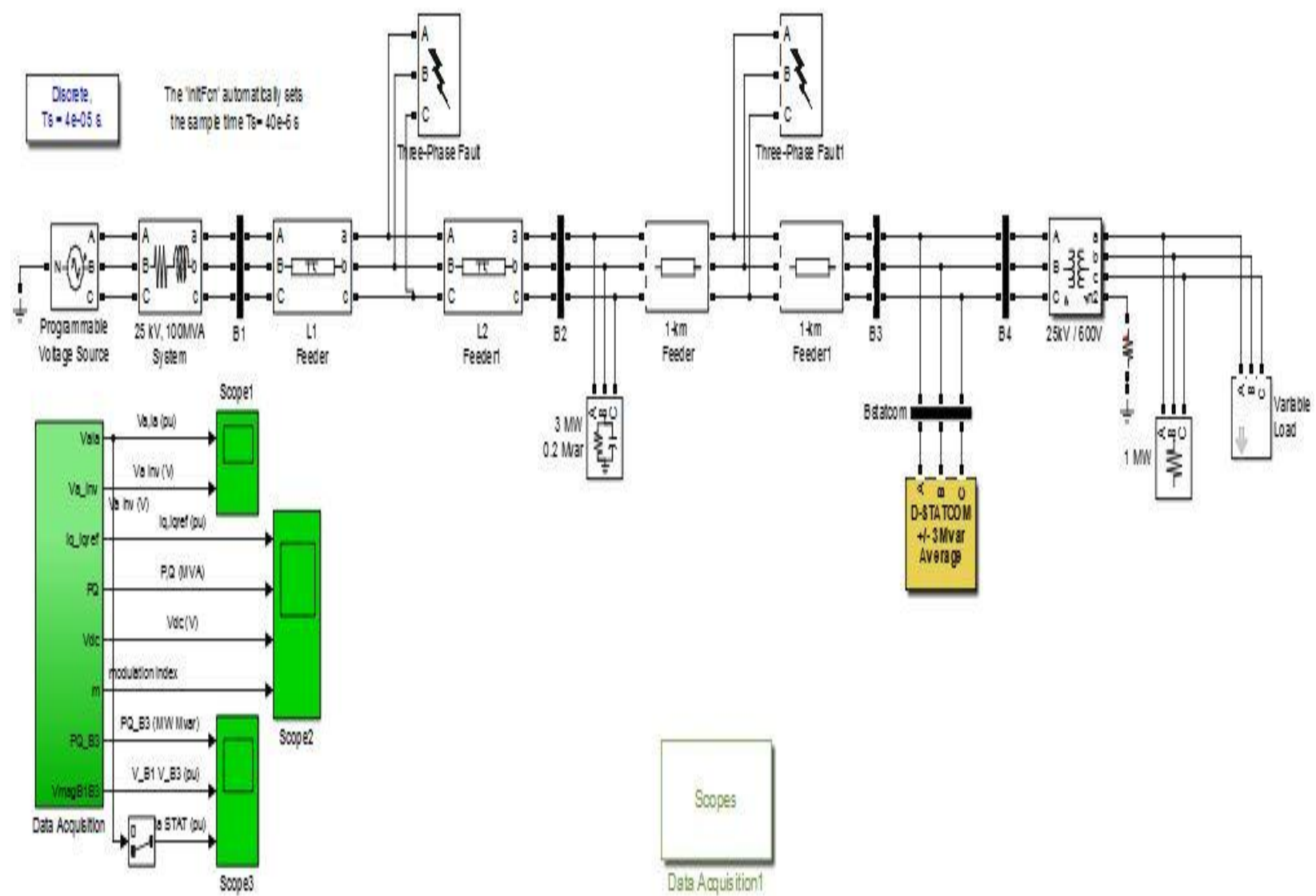

Figure 2 Simulink model of distribution network with D-STATCOM

3.1Measurement of voltage and current and preprocessing of data

At sampling frequency of 1,200 Hertz, 20 samples per each cycle, voltage and current waveforms have been generated from the model. The starting of one cycle obtained high value of voltage and current waveform because of the transient. Transient occurs due to switching operation of devices. The fault occur after the voltage source is increased by $6 \%$ at the time of $20 \mathrm{~ms}$. The voltage is decreases and current is increases during the fault. The Power system model is simulated in the MATLAB Simulink software and obtained fundamental components of three phase voltage and current by using Discrete Fourier transform (DFT) from bus 1, 2 and 3. The fundamental components of three phase voltage and current of bus 2 is used as an input to the ANN module. The Figure 3 shows voltage and current waveforms of phase A-G (ground) fault in forward section at $1-\mathrm{km}$ from Bus-2, 10-ohm fault resistance and 0 -degree fault inception angle. The training 
process is fast and improved by using pre-processing of three phase voltage and current signals.

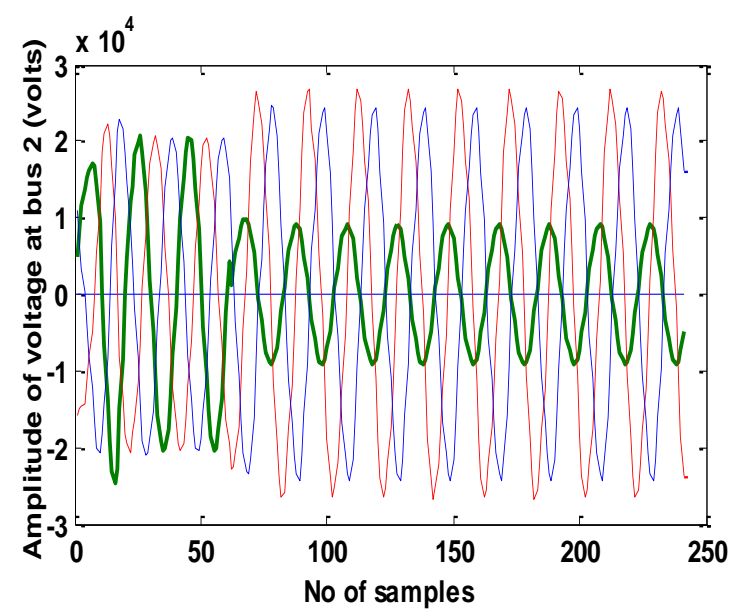

(a)

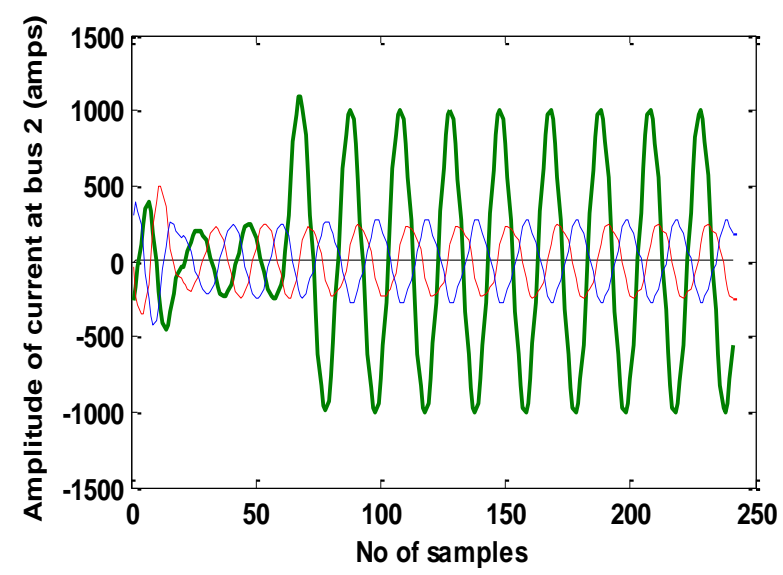

(b)

Figure 3 (a) Voltage and (b) current waveforms of bus 2 during phase A-G (ground fault)

\section{Artificial neural network (ANN)}

ANN is an information processing model inspired by the biological nervous system. An ANN is composed of a large number of highly interconnection processing elements (neurons) working in unison to solve specific problems. An ANN is configured for a specific application such as pattern recognition or data classification through learning process [17]. Artificial neural network is fast, simple, efficient and accurate technique. The training patterns are required. It is used for linear as well as non-linear model. ANN is a programming technique, and can easily solve the linear and non-linear problems for fault detection, fault classification and section identification. For best results, the factors that need to be appropriately selected are
- Selection of numbers of layers

- Number of neurons in each layer

- Selection of activation functions

- Learning algorithm parameters

Figure 4 shows one way connection of Feed forward network from input to output layer. In feed forward neural network, back propagation algorithm is applied to obtain the good results.

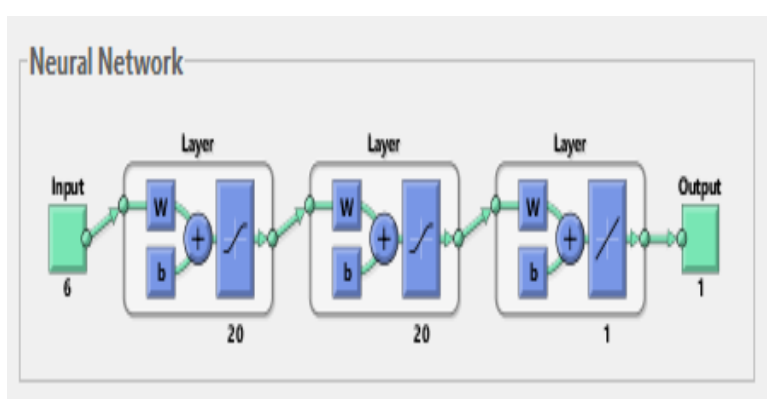

Figure 4 Architecture of ANN

\section{Training and testing}

The model of distribution network with DSTATCOM is built in MATLAB/ Simulink and ANN algorithm is used. The Levenberg-Marquardt backpropagation based algorithm is used for training the neural network. The training data set consists of total (3 fault resistances $* 39$ fault lengths $* 3$ fault inception angles $* 11$ types of faults $=3861$ ) fault cases and one no-fault case is added. Since, it is a supervised learning method so Target is needed for learning process. Training is done by taking activation function which are (tansig, tansig) and two hidden layers $(20,20)$ and checking the regression plot is accurate.

Table 1 shows, different fault cases, variation in fault parameters is consider in training data , 11fault types have been simulated with different fault inception angle $(0,45,90)$ degree and different fault resistance $(0,50,100) \mathrm{ohm}$ at different fault distance, and no fault samples also considered.

Table 1 Training pattern

\begin{tabular}{ll}
\hline $\begin{array}{l}\text { Training } \\
\text { pattern fault } \\
\text { length }(\mathbf{K m})\end{array}$ & $\begin{array}{l}\text { Reverse section Is 21 Km, Fault } \\
\text { increase in each 1 step }\end{array}$ \\
\cline { 2 - 2 } $\begin{array}{l}\text { forward section is } 2 \mathrm{~km} \text {, fault increase } \\
\text { in each } 0.1 \text { step }\end{array}$ \\
$\begin{array}{l}\text { Fault inception } \\
\text { angle in degree }\end{array}$ & $0,45,90$ \\
$\begin{array}{l}\text { Fault resistance } \\
\text { (ohm) }\end{array}$ & $0,50,100$ \\
Type of fault & A-G, B-G, C-G, AB, BC, CA, AB-G, \\
& BC-G, CA-G, ABC, ABC-G \\
\hline
\end{tabular}




\subsection{Fault detection}

For fault detection, six inputs are provided to the neural network, which are three phase voltages (VA, VB and VC) and three phase currents (IA, IB and IC). For developing of data set for training, all different eleven types of faults and no-fault conditions are also considered. The training data set consists of total ( 3 fault resistances $* 39$ fault lengths $* 3$ fault inception angles $* 11$ types of faults $=3861$ ) fault cases and one no-fault case is added. The output of neural network is in form of ' 0 ' and ' 1 ' ('no'or 'yes'), which shows ' 0 'for nofault data and ' 1 ' for faulted data. Figure 5(a) shows the testing result during B-C fault at $5.45 \mathrm{~km}$ reverse section from bus 2 and 30 degree fault inception angle and the top figure 5(a) represent the instantaneous value of three phase voltage and middle represent the instantaneous value of three phase current and bottom represent the output result for the detection. Similarly Figure 5(b) shows the testing result during BC-G fault at $0.55 \mathrm{~km}$ forward section from bus 2 , and 30 degree fault inception angle, the top two figure represents the instantaneous value of three phase voltage and current in which clearly visible that the voltage of phase $\mathrm{B}$ and $\mathrm{C}$ decreases and the current of same phase is increases and the output shows the fault occur at $51.3891 \mathrm{~ms}$ of time; relay operates with in $1.0909 \mathrm{~ms}$.

Thus the proposed relay take maximum $2.9 \mathrm{~ms}$ time to detect the forward fault.

\subsection{Section identification}

The six inputs provide to the neural network and getting 2 outputs. The section identification is done at middle bus (bus2) and it checks whether the fault has occurred in forward direction or reverse direction. Training is done with two activation function's (tangig, tansig), two hidden layer $(20,20)$ and checking the regression plot is accurate as same process employed in detection. After testing the two outputs get from neural network in the form of ' 0 ' or ' 1 '. First output is reverse section and second is forward section. Figure $6(a)$ shows the fault occur at $5.45 \mathrm{~km}$ reverse section from bus $2,30 \mathrm{ohm}$ fault resistance, $30 \mathrm{~m}$ degree fault inception angle and phase BC fault. The top plot, represents the output of reverse section and the bottom plot represent the output of forward section, the output of ANN based detector and direction estimator is ' 0 ' up to $52.48 \mathrm{~ms}$ of time; indicating there is no fault in the system. After $52.48 \mathrm{~ms}$ of time it starts increasing, which shows that there is a fault in reverse line section and reaches to 1 in $53.31 \mathrm{~ms}$ time thus the proposed relay take $1.9 \mathrm{~ms}$ time to detect the reverse fault. Similarly Figure $6(b)$ shows the testing result at $0.55 \mathrm{~km}$ forward section from bus $2,10 \mathrm{ohm}$ fault resistance, 30 degree fault inception angle and phase BC-G (ground) fault and takes $2 \mathrm{~ms}$ time to detect the fault.

\subsection{Fault classification}

The same process which was employed in detection is used in classification. Six inputs ( three phase voltage and three phase current) are taken but the neural network takes four outputs A, B, C and G, which should be ' 0 ' for no fault and ' 1 ' if there is any fault. According to various fault condition, various possibilities can be represented. The neural network which is proposed can distinguish accurately between eleven faults. Two modules have been designed for fault classification according to the type of fault (LG, LLG, LLLG) and (LL, LLL) because training matrix is very large, the complexity increases and it takes more time to train the data. One data set contains single line to ground fault, double line to ground fault and triple line to ground fault. Second data set contains double line fault and triple line fault. Training is done using two hidden layers $(20,20)$ and activation functions (tansig, tansig)
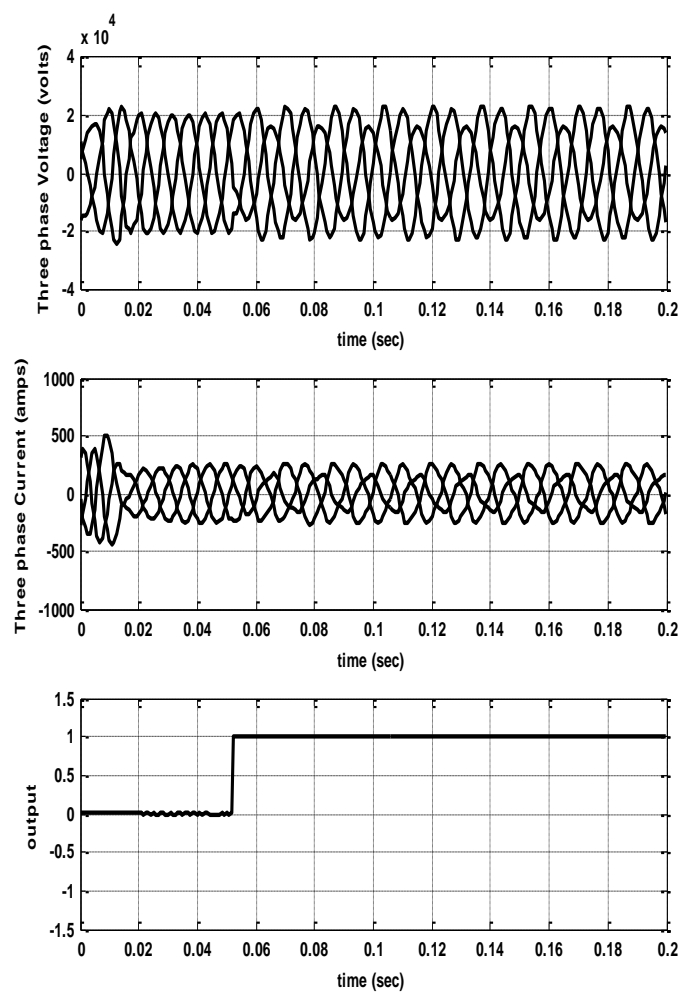

(a) 

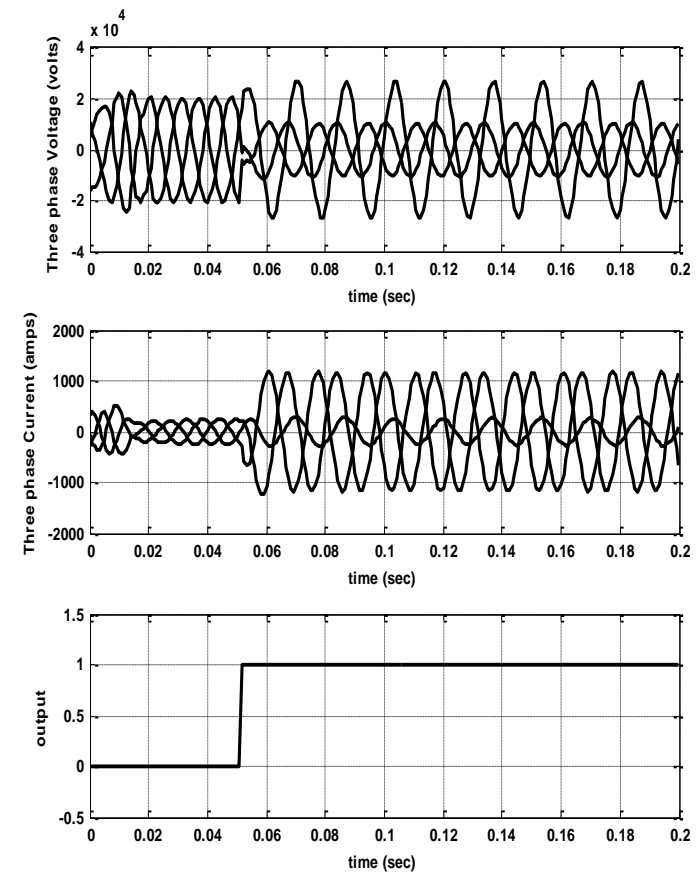

(b)

Figure 5 (a) Three phase Voltage, Current and detector output during phase B-C fault at $5.45 \mathrm{~km}$ from Bus 2 with fault resistance of $30 \mathrm{ohm}$ at time $51.3891 \mathrm{~ms}$

(b). Three phase Voltage, Current and detector output during phase B-C fault at $0.55 \mathrm{~km}$ from Bus 2 with fault resistance of $10 \mathrm{ohm}$ at time $51.3891 \mathrm{~ms}$
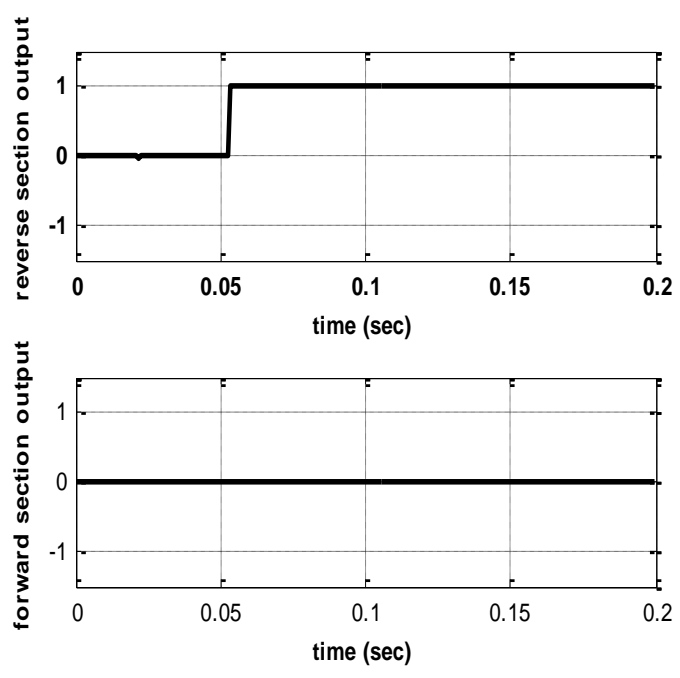

(a)
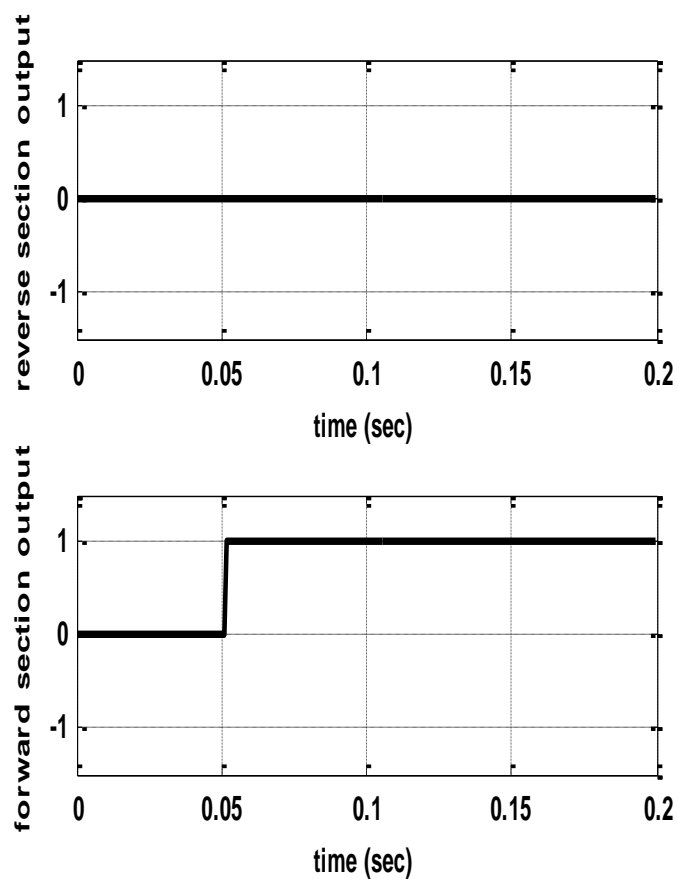

(b)

Figure 6 (a) Reverse section output and Forward section output during phase B-C fault at $5.45 \mathrm{~km}$ from Bus 2 with fault resistance of $30 \mathrm{ohm}$ at time $51.3891 \mathrm{~ms}$

(b) Reverse section output and Forward section output during phase B-C fault at $0.55 \mathrm{~km}$ from Bus 2 with fault resistance of $10 \mathrm{ohm}$ at time $51.3891 \mathrm{~ms}$

The regression plot and performance curve prove that the training is accurate. After training, testing is done by taking single fault resistance, single fault inception angle and single fault length with one type of fault. The test result for fault classification is shown in figure in which taken same parameters as used in fault detection. In fault classification the relay operates for forward direction, the results shows for forward section only. Figure 7 shows the testing result at $0.55 \mathrm{~km}$ forward section from bus $2,10 \mathrm{ohm}$ fault resistance, 30 degree fault inception angle and phase BC-G (ground) fault, the outputs of figure show that Phase-B goes high(1) at $52.48 \mathrm{~ms}$ time, Phase-C goes high(1) at $52.48 \mathrm{~ms}$ time and $\mathrm{G}$ (ground) goes high (1) at $52.48 \mathrm{~ms}$ time with other output phase-A goes low (0) and conforming that it is double line to ground fault (BC-G). 

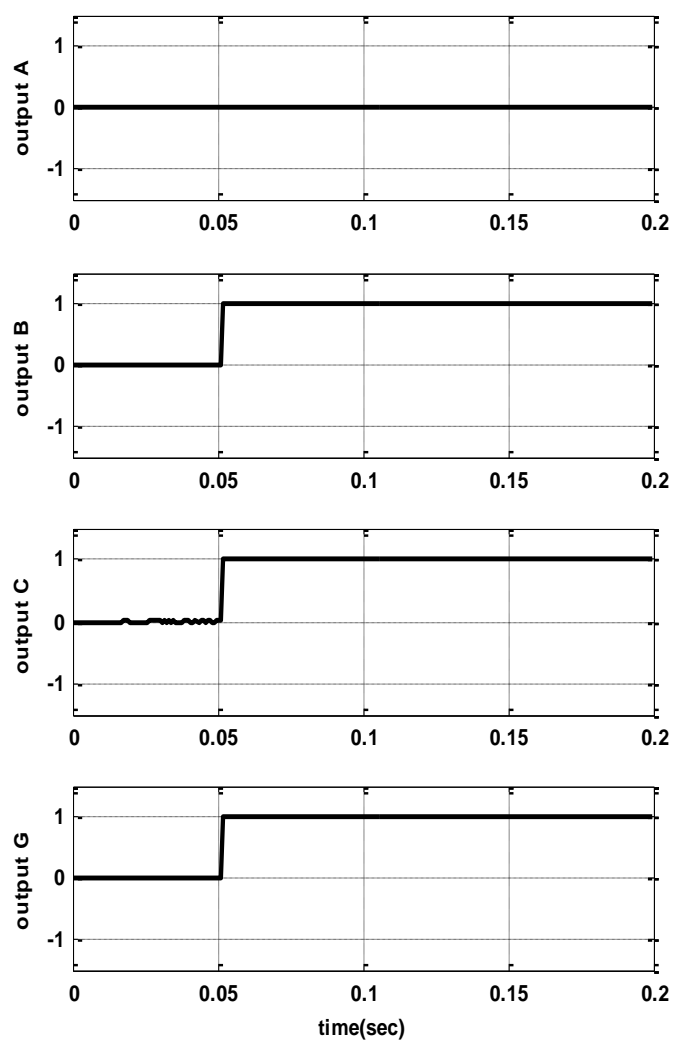

Figure 7 Test result for BC-G fault at $0.55 \mathrm{~km}$ from Bus 2 at fault inception time is $51.3891 \mathrm{~ms}$ and fault resistance of $10 \mathrm{ohm}$

\section{Conclusion and future scope}

The proposed method is simple and accurate technique for fault detection, fault classification and section identification (forward or reverse) which gives successful result under various fault conditions. The fundamental components of three phase voltage and current are used as an input to the neural network. For training Levenberg-Marquardt, backpropagation algorithm is used in neural network. Advantage of the proposed method is suitable for different fault conditions such as fault resistance, fault inception angle, fault type, fault distance, etc. The result gives high accuracy and exact operation of proposed fault detection, classification, section identification approach. With advent of smart grid technologies, the use of ANN based relays will help in fast fault analysis replacing the conventional relays and the use of D-STATCOM will help to maintain the voltage profile thereby increasing the reliability over distribution network.
Appendix

System Parameters of Figure 2 (Base MVA=100)

A 3-phase ac source:

Rated voltage: $25 \mathrm{kV}$

Line parameter of $21 \mathrm{~km}$ Feeder:

Positive sequence resistance: $0.1153 \Omega / \mathrm{km}$

Zero sequence resistance: $0.3963 \Omega / \mathrm{km}$

Positive sequence inductance: $1.048 \mathrm{e}-3 \mathrm{H} / \mathrm{km}$

Zero sequence inductance: $2.730 \mathrm{e}-3 \mathrm{H} / \mathrm{km}$

Positive sequence capacitance: $11.33 \mathrm{e}-9 \mathrm{~F} / \mathrm{km}$

Zero sequence capacitance: $5.338 \mathrm{e}-9 \mathrm{~F} / \mathrm{km}$

Line length: $21 \mathrm{~km}$

Line parameter of $2 \mathrm{~km}$ Feeder:

Positive sequence resistance: $0.1153 \Omega / \mathrm{km}$

Zero sequence resistance: $0.3963 \Omega / \mathrm{km}$

Positive sequence inductance: $1.048 \mathrm{e}-3 \mathrm{H} / \mathrm{km}$

Zero sequence inductance: $2.730 \mathrm{e}-3 \mathrm{H} / \mathrm{km}$

Positive sequence capacitance: $0 \mathrm{~F} / \mathrm{km}$

Zero sequence capacitance: $0 \mathrm{~F} / \mathrm{km}$

Line length: $2 \mathrm{~km}$

$25 \mathrm{kV}+/-3$ Mvar DSTATCOM:

DC voltage (controller): 2400

Cut off frequency: 2000

Capacitor: 10000e-6 F

Transformer:

Rated voltage: $25 \mathrm{kV} / 600 \mathrm{~V}$

Load:

Load1: 1MW

Load2: variable load

Nominal voltage: $600 \mathrm{~V}$

Current: $3000 \mathrm{amp}$

Sample time: $4 \mathrm{e}-5 \mathrm{~s}$

\section{Acknowledgment}

The author wish to acknowledge the Department of Electrical Engineering, National Institute of Technology Raipur for research facilities provided to conduct this project.

\section{Conflicts of interest}

The authors have no conflicts of interest to declare.

\section{References}

[1] Lakavath R, Kumaraswamy K, Sahithi S, Naresh G. Design and implementation of flexible d-statcom for mitigating power quality problems and improve the distribution system performance. 2014; 4(1): 404-13.

[2] Giroux P, Sybille G, Le-Huy H. Modeling and simulation of a distribution STATCOM using simulink's power system blockset. In annual conference of the IEEE industrial electronics society 2001 (pp. 990-4). IEEE.

[3] Yadav A, Thoke AS. ANN based directional fault detector/classifier for protection of transmission lines. 
International Journal of Computer Science \& Information Technologies. 2011; 2(5): 2426-33.

[4] Jia-Li H, Yuan-hui Z, Nian-ci Y. New type power line carrier relaying system with directional comparison for EHV transmission lines. IEEE Transactions on Power Apparatus and Systems. 1984:429-36.

[5] Johns AT. New ultra-high-speed directional comparison technique for the protection of EHV transmission lines. In IEE proceedings C-generation, transmission and distribution 1980 (pp. 228-39). IET.

[6] Xia YQ, He JL, Li KK. A reliable digital directional relay based on compensated voltage comparison for EHV transmission lines. IEEE Transactions on Power Delivery. 1992; 7(4):1955-62.

[7] Yadav A, Thoke AS. Transmission line fault distance and direction estimation using artificial neural network. International Journal of Engineering, Science and Technology. 2011;3(8):110-21.

[8] Altaie AS, Asumadu J. Fault detection and classification for compensating network using combination relay and ANN. In 2015 IEEE international conference on electro/information technology (EIT) 2015 (pp. 351-6). IEEE.

[9] Swetapadma A, Yadav A. Time domain complete protection scheme for parallel transmission lines. Ain Shams Engineering Journal. 2016; 7(1):169-83.

[10] Swetapadma A, Yadav A. High-speed directional relaying using adaptive neuro-fuzzy inference system and fundamental component of currents. IEEJ Transactions on Electrical and Electronic Engineering. 2015; 10(6):653-63.

[11] Yadav A, Swetapadma A. Enhancing the performance of transmission line directional relaying, fault classification and fault location schemes using fuzzy inference system. IET Generation, Transmission \& Distribution. 2015; 9(6):580-91.

[12] Jamil M, Sharma SK, Singh R. Fault detection and classification in electrical power transmission system using artificial neural network. Springer Plus. 2015.

[13] Gupta OH, Tripathy M. An innovative pilot relaying scheme for shunt-compensated line. IEEE Transactions on Power Delivery. 2015; 30(3):1439-48.

[14] Abdelaziz AY, Ibrahim AM. A hybrid wavelet-ANNbased protection scheme for FACTS compensated transmission lines. International Journal of Intelligent Systems and Applications. 2013; 5(7):23.
[15] Verma A, Yadav A. ANN based fault detection \& direction estimation scheme for series compensated transmission lines. In IEEE international conference on electrical, computer and communication technologies 2015 (pp. 1-6). IEEE.

[16] El-Zonkoly AM, Desouki H. Wavelet entropy based algorithm for fault detection and classification in FACTS compensated transmission line. International Journal of Electrical Power \& Energy Systems. 2011; 33(8):1368-74.

[17] Sivanandam SN, Deepa SN. Principles of soft computing. John Wiley \& Sons; 2007.

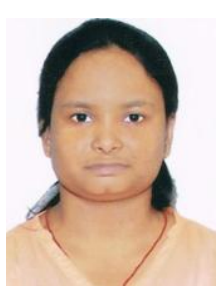

Garima Netam graduated B.E. in Electrical Engineering from GIMT, Chhattisgarh Swami Vivekanand Technical University, CG, India, in the year 2013 and pursuing her M.Tech from National Institute of Technology, Raipur, CG, India.

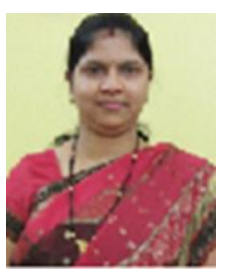

Anamika Yadav did her B.E. in Electrical Engineering from RGPV Bhopal, India, in the year 2002. She acquired her M.Tech Degree in Integrated Power System from V.N.I.T., Nagpur, India, in 2006 and Ph.D. degree in Electrical Engineering from CSVTU, Bhilai, with research centre at NIT, Raipur, C.G., India, in 2010. She worked as Assistant Engineer in the Chhattisgarh State Electricity Board, Raipur, CG, India, for 4.8 years. She joined National Institute of Technology Raipur, CG, India, on March 2009 as Assistant Professor in the Department of Electrical Engineering. Her research interest includes application of soft computing techniques to Power System protection. Recently she has been elevated to senior member IEEE. She is also the member of IET, IE(I) since 2009. 